\title{
CARTA DOS EDITORES CONVIDADOS
}

\section{Em defesa das fontes em tempos incertos}

Como novos editores associados da revista História, Ciências, Saúde-Manguinhos (HCSM), gostaríamos de convidá-los a colaborar na seção "Fontes". Identificar e divulgar fontes de pesquisa tem um significado que extrapola a mera descrição documental. Trata-se de contextualizar e criticar documentos, em seus múltiplos formatos, apontando limites e potencialidades de sua exploração no campo da pesquisa histórica; mais do que isso, tratase de operar uma historicização radical (Oliveira, 2007), capaz de restituir os jogos de força que atuaram em sua produção, circulação e institucionalização.

Como sabe a maioria dos historiadores, a análise crítica de um documento ou de um conjunto documental é requisito para uma boa investigação histórica. As fontes fornecem não apenas as evidências para o trabalho de interpretação dos historiadores, funcionando como condição de sua validação, mas descrevem percursos, indicam agências e permitem comparações. No momento em que a ciência aberta está sendo discutida, o estudo e a divulgação de fontes ganham novo impulso, ao conferir mais visibilidade e transparência à pesquisa e ao potencializar a interlocução entre os pares.

De fato, a configuração da história como disciplina nasceu da instituição de métodos rigorosos de crítica às fontes. Comprova-o o roteiro de temas mais debatidos nos manuais do século XIX que instituíram a história como ciência do conhecimento do passado. Ainda que muitas reflexões posteriores tenham denunciado o positivismo que embasou os primeiros tempos da disciplina, abalada também, na segunda metade do século XX, por críticas ao racionalismo aplicado à interpretação dos fenômenos sociais e à própria autoridade do texto histórico, as últimas décadas têm sido caracterizadas por um "retorno" às fontes que se vale das críticas ao arquivo e a seu concurso na constituição de "culturas do conhecimento" (Head, set. 2010), perspectiva especialmente potente no campo dos estudos decoloniais. Nesse mesmo diapasão, emergem estudos que tomam arquivos e coleções como objeto de pesquisa, e não apenas como fonte do conhecimento histórico, investindo em suas conexões com os campos da memória e das identidades (Burton, 2005).

No contexto atual, o retorno às fontes ganha novo significado. Diante da propagação de discursos francamente distorcidos sobre o passado, nos quais se incluem os negacionismos e os revisionismos conservadores, muitas vezes propagados por meio das mídias digitais, as fontes históricas emergem como caução, juntamente com os procedimentos que garantem sua verificação. Segundo um dos próceres do movimento de retorno às fontes: "O historiador não exige que pessoas acreditem em sua palavra, sob o pretexto de ser um 
profissional conhecedor do seu ofício ..., mas oferece ao leitor a possibilidade de verificar as suas informações" (Prost, 2008, p.55).

No momento em que história e historiadores estão sob ataque, bem como o discurso científico de maneira geral, as fontes de pesquisa e os procedimentos científicos que validam seu uso ganham nova dimensão e importância. Por meio delas podemos retomar o debate sobre o estatuto do conhecimento histórico no século XXI, seja para refletir sobre manipulações e distorções frequentemente empregadas para legitimar políticas e interesses (Macmillan, 2009), seja para elucidar como se produz história na era global (Hunt, 2014) ou diante de um ceticismo radical propagado pelo chamado pós-modernismo (Maza, 2017). Ao manter uma seção dedicada à reflexão sobre as fontes, entendidas em sentido amplo, HCSM confirma seu compromisso com uma história que tem o arquivo e a crítica à fonte como um dos pilares do trabalho historiográfico. Compromisso que acompanha a revista desde a sua fundação, indicando o posicionamento de seus editores diante das controvérsias que marcaram a disciplina e sua escrita nos últimos 25 anos.

A rubrica "Fontes" abarca um vasto repertório de possibilidades. Confirma-o a própria trajetória da seção. Em sua primeira edição, v.1, n.1, jul.-out. 1994, ela se intitulava "Documentos" e fazia par com a seção "Bibliotecas \& Coleções". A divisão parece ter confundido os leitores. Comprova-o a oscilação no uso da terminologia no primeiro ano do periódico. No v.1, n.2, nov. 1994-fev. 1995, a seção foi chamada de "Arquivos \& Documentos", e nela foi publicada uma apresentação escrita por Lina Rodrigues de Farias (nov. 1994-fev. 1995), seguida de transcrição traduzida do documento "Public Health situation and work of International Health Board in Brazil", escrito no ano de 1920 por Wickliff Rose, da Junta Internacional de Saúde da Fundação Rockefeller. O título do texto fazia menção direta ao nome da seção: "Arquivo Rockefeller". No entanto, no mesmo número, a seção irmã, "Bibliotecas \& Coleções", trazia um texto de Flavio Edler (nov. 1994fev. 1995) com o título "Fontes alternativas para uma história das ciências".

Atento ao problema de uma definição estrita do que vem a ser documento em história, em sua terceira edição, v.2, n.1, mar.-jun. 1995, HCSM instituiu a seção "Fontes". A novidade foi justificada pelo editor Sergio Goes de Paula (mar.-jun. 1995, p.5): "As seções 'Arquivos \& Documentos' e ‘Bibliotecas \& Coleções' transformaram-se em uma só, 'Fontes'. Com isso, parece-nos que acabamos com um certo artificialismo que vinha nos incomodando e nos trazendo algumas dificuldades; e quando nem os editores sabem distinguir uma seção da outra, é que está feia a coisa".

A recuperação dessa trajetória ilustra eventuais dúvidas do leitor quanto ao que enviar para a seção. Além disso, um breve passeio pelo perfil dos artigos pode servir de bússola de orientação aos interessados que não tenham ainda visitado o valioso repertório de artigos publicados e integralmente disponibilizados. Eis algumas possibilidades: apresentação de projetos de constituição de acervos ou de memória institucionais; levantamento e sistematização de fundos documentais; divulgação de coleções de documentos existentes em arquivos privados ou públicos; apresentação de diários, periódicos científicos e prontuários pessoais e suas respectivas potencialidades como fontes históricas; análise de fontes oficiais como mensagens de presidentes de Estado e sua importância para a política científica e tecnológica; traduções de textos raros, antecedidas por apresentação sobre sua pertinência 
para a história da ciência; apresentação de arquivos particulares e/ou institucionais e dos seus respectivos acervos e coleções.

Vale destacar que HCSM raramente deixou de publicar ao menos um texto de "Fontes" em seus números. São 25 anos acompanhando a própria abertura do campo para fontes que emergem de tempos em tempos. É o que se vê, por exemplo, diante da necessidade de justificar a presença de artigo que versa sobre bibliotecas virtuais em uma revista de história da ciência. No texto "Bibliotecas eletrônicas", a pesquisadora Ruth B. Martins abre a seção "Bibliotecas \& Coleções" com a seguinte ressalva: "Pode surpreender o leitor que uma revista com o perfil da Manguinhos dê, aparentemente, as costas para a história e inaugure sua seção Bibliotecas \& Coleções discorrendo sobre comunicações entre computadores" (Martins, jul.-out. 1994, p.135). Em salto para a seção "Fontes" do v.26, n.1, jan.-mar. 2019, encontramos a mesma preocupação de atualizar os leitores acerca das relações entre acesso às fontes e recursos tecnológicos. O título agora é "Democratizar a informação para o desenvolvimento do conhecimento: a ampliação do acesso ao acervo documental das ciências e da saúde na Fiocruz", e a pesquisadora Nercilene Santos da Silva Monteiro (jan.mar. 2019, p.299) abre o texto com o seguinte comentário: "A gestão de documentos físicos e digitais é apontada como componente central para constituir fontes de informação para o presente e fontes históricas para o futuro".

Dois outros artigos reforçam a pertinência social e científica dessa seção e indicam a diversidade de possibilidades que ela abarca. Em "A Guerra e as laranjas: uma palestra radiofônica sobre o valor alimentício das frutas nacionais (1940)", Jaime Rodrigues e Maria da Penha Costa Vasconcellos transcreveram a palestra pronunciada pelo sanitarista conhecido como Paula Souza, na Rádio Educadora Paulista no dia 16 de abril de 1940, portanto, no contexto da Segunda Guerra Mundial. Segundo os autores, a emissão radiofônica visava defender "o valor nutritivo e a necessidade de consumo de laranja como ato patriótico" (Rodrigues, Vasconcellos, out.-dez. 2007, p.1401).

O segundo texto trata sobre surtos epidêmicos na Bahia durante os anos 1920. Com o título "Os mosquitos e o Estado no relatório do chefe do Serviço de Saneamento e Profilaxia Rural da Bahia, 1922", Heloísa Helena Rocha chama a atenção para a correlação do presente com o passado ao afirmar:

Novamente os mosquitos - que tantas vidas têm roubado e tantos estragos têm produzido, nos surtos recorrentes de dengue e nos episódios recentes de chikungunya e zika vírus - assombram a vida dos brasileiros e daqueles que cruzam as fronteiras deste imenso país, colocando todos em sobressalto e reclamando a ação dos poderes públicos. Medo, pânico, riscos, ameaça, alerta, emergência são alguns dos termos que permeiam a linguagem que registra o aumento do número de casos confirmados da doença e de mortes (Rocha, jan.-mar. 2018, p.262).

Mais do que ilustrar a multiplicidade de fontes que podem ser objeto de análise, os textos têm algo a dizer sobre o papel dessa seção para os debates sobre ciência: eles testemunham as estratégias de divulgação de notícias de caráter científico, o uso de registros sonoros e de relatórios oficiais como fonte histórica, assim como remetem ao papel social, político e científico que os artigos da seção podem assumir. Não menos importante para a rubrica 
"Fontes" é o fato de se tratar de documentos inéditos. Por meio dos textos é possível não apenas enunciar uma novidade, como marcar o lugar das pesquisas em desenvolvimento no campo científico de forma geral, e na história de forma particular.

Esperamos, com essa explanação, ter animado os(as) colegas a enviarem contribuições para a seção "Fontes" de HCSM. Estamos motivados a dar continuidade ao trabalho desenvolvido até hoje, sempre abertos às novas miradas sobre o potencial de documentos, periódicos, objetos, coleções, mas também bases de dados e páginas da internet. A revista recebe contribuições em fluxo contínuo, devendo o(a) autor(a) ter a titulação mínima de mestre. Os manuscritos encaminhados a essa seção não devem exceder cinco mil palavras. Eles serão submetidos a pareceristas externos, tendo as mesmas prerrogativas dos artigos publicados na seção "Análise".

Esperamos contar com a submissão de colaborações e nos colocamos à disposição para quaisquer dúvidas ou consultas.

\section{REFERÊNCIAS}

BURTON, Antoinette.

Introduction: archive fever, archive stories. In: Burton, Antoinette (Ed.). Archive stories: facts, fictions, and the writing of history. Durham; London: Duke University Press. 2005.

EDLER, Flavio.

Fontes alternativas para uma história das ciências. História, Ciências, Saúde-Manguinhos, v.1, n.2, p.89100. Disponível em: <http://dx.doi.org/10.1590/S0104-59701995000100008>. Acesso em: 7 out. 2019. nov. 1994-fev. 1995.

FARIA, Lina Rodrigues de.

Arquivo Rockefeller. História, Ciências, Saúde - Manguinhos, v.1, n.2, p.117-128. Disponível em: <http:// dx.doi.org/10.1590/S0104-59701995000100010>. Acesso em: 7 out. 2019. nov. 1994-fev. 1995.

HEAD, Randolph.

Preface: Historical research on archives and knowledge cultures - an interdisciplinar wave. Archival Science, v.10, n.3, p.191-194. Disponível em: <https://doi.org/10.1007/s10502-010-9130-1>. Acesso em: set. 2010.

HUNT, Lynn.

Writing history in the global era. New York: Norton \& Company. 2014.

MACMILLAN, Margaret.

The uses and abuses of history. London: Profile Books. 2009.

MARTINS, Ruth B.

Bibliotecas eletrônicas. História, Ciências, Saúde - Manguinhos, v.1, n.1, p.135-140. Disponível em: <http://dx.doi.org/10.1590/S0104-59701994000100013>. Acesso em: 7 out. 2019. jul.-out. 1994.

MAZA, Sarah.

Thinking about history. Chicago: The University of Chicago Press. 2017.

MONTEIRO, Nercilene Santos da Silva.

Democratizar a informação para o desenvolvimento do conhecimento: a ampliação do acesso ao acervo documental das ciências e da saúde na Fiocruz. História, Ciências, Saude - Manguinhos, v.26, n.1, p.299318. Disponível em: <http://dx.doi.org/10.1590/s0104-59702019000100017>. Acesso em: 7 out. 2019. jan.-mar. 2019.

OLIVEIRA, João Pacheco.

O retrato de um menino Bororo: narrativas sobre o destino dos índios e o horizonte político dos museus, séculos XIX e XXI. Tempo, v.12, n.23, p.73-99. Disponível em: <https://dx.doi.org/10.1590/ S1413-77042007000200006>. Acesso em: 10 out. 2019. 2007. 
PAULA, Sergio Goes de.

Carta do editor. História, Ciências, Saúde - Manguinhos, v.2, n.1, p.5. Disponível em: <http://dx.doi. org/10.1590/S0104-59701995000200001>. Acesso em: 7 out. 2019. mar.-jun. 1995.

PROST, Antoine.

Doze lições sobre a história. Belo Horizonte: Autêntica. 2008.

ROCHA, Heloísa Helena.

Os mosquitos e o Estado no relatório do chefe do Serviço de Saneamento e Profilaxia Rural da Bahia, 1922. História, Ciências, Saúde - Manguinhos, v.25, n.1, p.261-279. Disponível em: <http://dx.doi. org/10.1590/s0104-59702018000100015>. Acesso em: 7 out. 2019. jan.-mar. 2018.

RODRIGUES, Jaime; VASCONCELLOS, Maria da Penha Costa.

A guerra e as laranjas: uma palestra radiofônica sobre o valor alimentício das frutas nacionais (1940). História, Ciências, Saúde - Manguinhos, v.14, n.4, p.1401-1414. Disponível em: <http://dx.doi. org/10.1590/S0104-59702007000400016>. Acesso em: 7 out. 2019. out.-dez. 2007.

\author{
Luciana Heymann ${ }^{i}$ \\ i Pesquisadora, Casa de Oswaldo Cruz/Fiocruz. \\ Rio de Janeiro - RJ - Brasil \\ orcid.org/0000-0002-5715-8824 \\ luciana.heymann@fiocruz.br \\ Rogério Rosa Rodrigues ${ }^{i i}$ \\ ii Professor, Universidade do Estado de Santa Catarina. \\ Florianópolis - SC - Brasil \\ orcid.org/0000-0002-5189-7095 \\ rogerio.rodrigues@udesc.br
}

